\title{
Discrepancies between clinical needs and helpseeking behaviors in co-occurring posttraumatic stress and alcohol use disorders
}

\author{
Mario Müller ${ }^{1 *}$, Stephanie Rodgers ${ }^{1}$, Wulf Rössler ${ }^{1,2,3}$, Enrique \\ Castelao $^{4}$, Martin Preisig ${ }^{4}$, Vladeta Ajdacic-Gross ${ }^{1}$, Caroline Vandeleur ${ }^{4}$
}

${ }^{1}$ Department of Psychiatry, Psychotherapy and Psychosomatics, Zurich University Hospital of Psychiatry, Switzerland

${ }^{2}$ Collegium Helveticum, University of Zurich and Swiss Federal Institute of Technology, Zurich, Switzerland

${ }^{3}$ Institute of Psychiatry, Laboratory of Neuroscience (LIM 27), University of Sao Paulo, Sao Paulo, Brazil

${ }^{4}$ Department of Psychiatry, University Hospital of Lausanne, Switzerland

Word count Abstract: 200

Word count text body: 3,630

Number of Tables: 4

*Correspondence concerning this article should be addressed to:

Mario Müller, $\mathrm{PhD}$

Zurich University Hospital of Psychiatry

Department of Psychiatry, Psychotherapy and Psychosomatics

PO Box 1930, CH-8021 Zurich, Switzerland

Tel: 0041-44-296 7432

Fax: 0041-44-296 7449

E-mail: mario.mueller@dgsp.uzh.ch 


\begin{abstract}
Objective: The aim of the study was to compare subjects dually diagnosed with posttraumatic stress disorder (PTSD) and alcohol use disorder (AUD) to those with only one or none of these conditions regarding helpseeking needs and behaviors.
\end{abstract}

Method: Data from a large community sample $(\mathrm{N}=3,694)$ were used to assess the associations among lifetime PTSD and AUD, other psychiatric disorders, clinical characteristics and lifetime helpseeking behaviors derived from a semi-structured interview.

Results: Comorbid individuals had more severe clinical profiles and were more impaired than individuals with either PTSD or AUD alone or those with no/other psychiatric conditions. However, they did not differ in overall helpseeking behavior from any other group. Those with comorbid PTSD/AUD were even less likely than the other groups to seek help for depression and anxiety disorders through specific treatment facilities or the use of prescribed psychotropic drugs.

Conclusions: Despite a greater need for treatment the comorbid group did not seek more help than the others. Their lower use of prescribed drugs supports the self-medication hypothesis, suggesting that those individuals relieve their symptoms through higher alcohol use instead. Our findings underline the need for health care facilities to encourage help-seeking behavior in the aftermath of stressful life events.

Keywords: Community sample; AUD comorbid with PTSD; mental health care needs; helpseeking behavior; self-medication 


\section{Introduction}

The clinical presentation of posttraumatic stress disorder (PTSD) is frequently affected by a considerable amount of comorbid conditions, such as mood and anxiety disorders as well as increased suicidality $[1,2]$. Moreover, previous research has suggested that the course and clinical profile of PTSD might be especially complicated by the presence of comorbid alcohol use disorders (AUD) [3]. Indeed, those with dually diagnosed PTSD/AUD tend to have more comorbid conditions, greater impairment [4] and therefore poorer treatment outcomes than those with only one of the two conditions [5]. It is assumed that both conditions are functionally related whereof each of them contributes to the maintenance of the other one [6]. Conceptual models, such as the self-medication model, suggest that an increased use of alcohol may be seen as an attempt to cope with severe traumatic experiences [7-9]. Actually, the co-occurrence of PTSD and AUD is more prevalent among individuals with more severe traumatization, such as the experience of sexual abuse in childhood, in both clinical $[10,11]$ and epidemiological samples [2, 12].

In sum, due to a greater need for help one might expect that those with both conditions seek psychiatric help more frequently than those with one condition only $[13,14]$. In fact, in a helpseeking population, an overall higher service use was found in those with comorbid PTSD/AUD compared to those with PTSD alone [15] while other studies found AUD as a comorbid condition in general to decrease the likelihood of service use for anxiety disorders [16] and depression [17]. Unfortunately, most studies on this topic have relied on clinical samples, which hinder a naturalistic view of how an interplay of these two conditions might affect helpseeking behavior. To our knowledge there is only one study to date that investigated helpseeking behavior in individuals with comorbid PSTD and AUD from an epidemiological perspective [4]. Although their findings suggested greater clinical severity in individuals with comorbid PTSD/AUD than in those with PTSD alone, these groups did not differ in their help-seeking behavior [4]. However, the generalization of these results is 
limited since the authors did not adjust for other important factors that might affect or promote help-seeking behavior. Indeed, according to the behavioral model of mental health service use [18], the role of predisposing characteristics related to service use, such as individual rather than illness-related tendencies (e.g. age or gender), as well as enabling factors, that enable a person to make use of mental health services (e.g. socio-economic status, health insurance), should be determined. This, to our knowledge, has not been examined in individuals with comorbid PTSD/AUD so far.

On the one hand, it can be assumed that the comorbid condition of PTSD and AUD is associated with a more severe clinical representation of illness, which suggests a greater need for help. On the other hand, it has been suggested that the comorbid condition of AUD in individuals with PTSD might arise from an attempt to self-medicate their symptoms, which, in turn, might supersede their individual need for treatment. The purpose of the current study was to compare the objectively assessed need for treatment in terms of clinical characteristics as well as indicators of past help-seeking behavior among individuals with comorbid PTSD/AUD and those with either PTSD or AUD alone, in a large community sample. More precisely, we aimed to describe the comorbidity and other clinical correlates as indicators of illness severity as well as the helpseeking behaviors that were associated with these diagnostic conditions. A better understanding of discrepancies between objectively assessed clinical needs and the actual use of mental health services will allow for a targeted evaluation of comorbid conditions and integrated treatment interventions.

\section{Material and methods}

\section{Sample and procedure}


The data were collected within the PsyCoLaus study [19], a substudy of the larger CoLaus randomly selected population-based cohort study [20] of Lausanne, Switzerland. From 2003 to $2006, \mathrm{~N}=6,734$ subjects aged between 35 and 75 years were recruited for the first wave of CoLaus, which was designed to assess the prevalence of cardiovascular risk factors and diseases. Sixty-seven percent of the subjects of the CoLaus study in the age range between 35 and 66 years $(n=5,535)$ accepted the psychiatric exam (PsyCoLaus; see [19] for a detailed description). Ninety-two percent of them were Caucasians. The gender distribution of the PsyCoLaus sample (47\% males) did not differ significantly from that of the general population in the same age range. Although the youngest 5-year band of the cohort was underrepresented and the oldest 5-year band was overrepresented, participants of PsyCoLaus (mean age 50.9; $\mathrm{SD}=8.8$ years) and individuals who refused participation revealed comparable scores on the General Health Questionnaire (GHQ-12 [21]; French translation [22], which was completed during the somatic investigation (CoLaus).

For the present analyses, $\mathrm{N}=26$ subjects were excluded due to missing data on the screening item for traumatic exposure, leading to a final sample of $\mathrm{N}=3,694$ individuals. From those, $53 \%$ were females and the mean age was 49.60 years $(\mathrm{SD}=8.8)$. More than half of the sample $(52.76 \%)$ had basic education (i.e. completion of basic schooling until the age of 16 years, after which an apprenticeship was undertaken or a professional school was attended), $24.69 \%$ had higher education (i.e. completion of a school in which a certified profession was taught), and $21.47 \%$ had a university-type degree. Forty participants $(1.08 \%)$ reported that they had not completed compulsory school (i.e. they had left school before the age of 16 years). Socioeconomic status (SES) was assessed according to the Hollingshead's index [23]. The mean SES was $3.38(\mathrm{SD}=1.27)$, the average sample therefore belonged to the middle class. 
The study was approved by the Ethics Committee of the Lausanne University, Switzerland. All participants provided written consent after being informed of the goal and funding of the study.

\section{Measures}

The data of the PsyCoLaus study were derived from the French version [24] of the semistructured Diagnostic Interview for Genetic Studies (DIGS) [25]. In addition to demographic features, the French version of the DIGS comprises information on a broad spectrum of DSMIV Axis I and Axis II criteria (including AUD, which comprised both abuse and dependence) as well as on suicide behavior [19]. The PTSD and generalized anxiety disorders sections of the DIGS were based on the relevant sections of the French version [26] of the Schedule for Affective Disorders and Schizophrenia - Lifetime and Anxiety disorder version [27].

The following categories, were considered as additional comorbid conditions over lifetime (i.e., independently of whether one was diagnosed with PTSD or AUD): major depressive disorder (MDD), generalized anxiety disorder (GAD), simple phobia, social phobia, agoraphobia, obsessive-compulsive disorder (OCD), panic disorder, antisocial personality disorder, other substance use disorders (SUD; abuse or dependence of cannabis, solvent, hallucinogens, stimulants, cocaine, sedatives, or narcotics), and suicide attempts.

Information on overall helpseeking behavior was based on single items from the DIGS. Thus, questions were asked on whether a participant had sought professional help for emotional problems at any time during his/her life and if so, at what age for the first time. Furthermore, questions were asked on whether a participant was ever admitted to a psychiatric hospital for emotional problems (and if so, at what age for the first time) and on how many hospital stays he/she had had. Information on treatment for depression or anxiety disorders was obtained by 
asking whether he/she had ever received treatment in the corresponding chapters for depression or anxiety disorders. Information on drugs prescribed for depression or anxiety disorders was obtained by either asking whether a participant had ever taken medications for his/her nerves or any emotional or mental problems in general, and then again by asking whether he/she had ever received specific prescribed medication in the corresponding chapters for depression or anxiety disorders.

The French version of the DIGS as well as the anxiety sections of the SADS-LA revealed excellent inter-rater and fair to good test-retest reliability for major mood [28], substance use [29] and anxiety disorders [26]. To test the reliability of the PTSD section of the French version of the SADS-LA a three-year follow-up study on 176 psychiatric patients was conducted, which revealed a test-retest reliability of 0.69 for the PTSD diagnosis [30].

Interviewers were required to be masters-level psychologists and were trained over a twomonth period. In order to ensure ongoing supervision throughout the study, each interview and diagnostic assignment was reviewed by a senior psychologist who had extensive experience in conducting semi-structured interviews and in making DSM-IV diagnoses based on these interviews.

\section{Statistical analysis}

The study sample was stratified by diagnostic condition: 1.) AUD, 2.) PTSD, 3.) comorbid PTSD and AUD, as well as 4.) neither of these two conditions.

Descriptive statistics were computed for socio-demographic and clinical factors as well as help-seeking behaviors across subsamples. Frequencies are provided for categorical variables, means (M) and standard deviations (SD) for continuous variables. To examine overall variations across groups, Chi-square statistics for categorical variables and one-way analyses of variance (ANOVA) for continuous variables were calculated. In case of an overall 
significant effect bivariate multinomial regressions with changing reference categories were conducted to test for differences in categorical variables between subgroups, and Bonferroni post-hoc tests were conducted for continuous variables.

Subsequently, multinomial logistic regression models with odds ratios (OR) and 95\% confidence intervals $(95 \% \mathrm{CI})$ were calculated for all significant associations with helpseeking behaviors. All models were adjusted for socio-demographic characteristics (sex, age, education, SES), the number of comorbid disorders, and suicidal behavior.

All analyses were conducted using Stata/SE 12 [31].

\section{Results}

Four hundred and thirty-four participants (11.76\%) were diagnosed with AUD $(22.58 \%$ females) and N=147 (3.98\%) with PTSD (71.43\% females). After accounting for PTSD and AUD as dual and single diagnoses the corresponding prevalence rates for AUD alone, PTSD alone, and comorbid PTSD/AUD were $10.91 \%, 3.14 \%$, and $0.84 \%$, respectively. Age of onset of AUD or PTSD did not differ between single and dual diagnoses groups but, however, in the comorbid group the age of PTSD onset significantly preceded the AUD onset.

These diagnostic groups differed significantly regarding sex, education level, and SES but not regarding age (see Table 1). Accordingly, the highest proportion of female was found among individuals with PTSD alone followed by those with comorbid PTSD/AUD. Individuals with PTSD/AUD had received basic education more often but higher education less often than peers, while those with PTSD alone had not finished their compulsory school more often than the others. The proportion of university level degrees was comparable across groups. Individuals with PTSD alone had the lowest SES followed by the comorbid group and then 
the group with AUD alone. For more details on socio-demographic characteristics please refer to Table 1.

- insert Table 1 -

Table 2 displays distributions of clinical characteristics including trauma features and comorbidity. Accordingly, the most frequently reported lifetime trauma type was witnessing violence, followed by having been involved in an accident, being a victim of crime, the experience of sexual abuse, and being involved in acts of combat and/or war. Those participants with either PTSD/AUD or PTSD alone experienced these trauma types significantly more often than others, except for experiences of war or combat which were not different across groups. Childhood trauma, i.e. any of these trauma types experienced below the age of 16, and childhood sexual abuse in particular, was most prevalent among those with PTSD/AUD. Other types of childhood trauma did not differ between subjects with PTSD/AUD and PTSD.

Groups also differed significantly regarding other clinical characteristics including the presence of comorbid disorders, suicidal behavior, and functional impairment. Accordingly, the comorbid PTSD/AUD group had higher overall numbers of additional comorbid conditions than any other group. This group differed in most disorders from AUD and controls, except for other substance use disorders and antisocial personality disorders, which were significantly more frequent in PTSD/AUD and AUD than in the others. The rates of simple phobia did not differ among groups.

A history of a suicide attempt as well as the number of attempts was highest in the comorbid group followed by PTSD alone, which were both significantly different from controls and 
AUD (the latter also significantly higher than controls). The PTSD/AUD group was younger at first suicide attempt than those with AUD only. Controls had better overall and occupational functioning than those with single or dual PTSD and AUD. Furthermore, compared to the group with AUD alone, both the comorbid and PTSD group were more likely to suffer from higher occupational impairment and had a lower overall GAF score at the worst time. However, the comorbid group did not differ from the group with PTSD alone regarding functional impairment. More details on these inter-group comparisons are provided in Table 2.

- insert Table 2 -

Bivariate results revealed that helpseeking behavior systematically varied across groups (Table 3). Accordingly, the comorbid goup was younger when they first sought professional help and they were admitted to a psychiatric hospital more frequently than their peers. The group with PTSD alone had the highest rates of professional helpseeking for emotional problems but they were not significantly different from PTSD/AUD. Lifetime treatment as well as the use of prescribed drugs for depression or anxiety disorders was highest among those with PTSD followed by those with comorbid PTSD/AUD. Although, these numbers were higher than in AUD and controls, the PTSD only group did not significantly differ from the comorbid PTSD/AUD group. 
Multinomial logistic regressions (Table 4) showed that AUD and PTSD alone, but not those with the comorbid condition, were more likely to seek professional help for emotional problems than controls, after controlling for socio-demographic features and comorbidity. The comorbid group, however, was younger than any other group when they first sought help for emotional problems. Those with AUD were more likely to have ever been admitted to a psychiatric hospital than controls. Lifetime treatment for any depression or anxiety disorders was less likely in the comorbid group than in the others, even less likely than among controls. Specific treatment for depression was more likely in AUD compared to controls and PTSD. Specific treatment for anxiety disorders was, in contrast, more likely in PTSD than in AUD and also less likely in the comorbid group. The groups with AUD and PTSD alone were more likely to have ever used any prescribed drugs for depression or anxiety disorders than controls and PTSD/AUD. In particular, the use of specific medications for depression was more likely in AUD compared to controls and less likely in comorbid PTSD/AUD when compared to PTSD only. The specific use of medications for anxiety disorders was more likely in those with PTSD versus controls.

- $\quad$ insert Table 4 -

\section{Discussion}

The aim of the present study was to examine systematic variations between clinical characteristics and helpseeking behaviors among individuals with PTSD and AUD occurring as comorbid conditions versus those with only one of these conditions and controls in a large randomly-selected non-clinical sample. The data were collected using a semi-structured diagnostic interview administered by trained psychologists. 
Our data reveal that individuals with comorbid PTSD/AUD were exposed to more severe types of trauma and had higher levels of illness severity than those with either PTSD or AUD alone. More precisely, PTSD/AUD comorbidity was linked to childhood sexual abuse experiences, to more psychiatric comorbidity and suicidal behavior, and, to some extent, to greater impairment than only one of the two conditions [2, 12, 32]. Taken together, our results suggest that the co-occurrence of PTSD and AUD represents a highly impaired subtype of response to trauma.

As a consequence, one might expect to find a more distinctive pattern of helpseeking behaviors in this subgroup. However, despite an obviously greater need for help our data show that the comorbid group was not more likely to seek help for apparent mental health problems. Although this comorbid group reported a higher number of past psychiatric admissions than those with either condition alone, these differences did not hold after adjustment for socio-demographic features and comorbidity. Our data, however, suggest that those with comorbid PTSD/AUD were significantly younger when they first sought professional help than those with either PTSD or AUD alone, which might be partially explained by their more adverse early life circumstances [33]. Furthermore, those with comorbid PTSD/AUD were less likely to seek help for depression and anxiety disorders through specific treatment facilities. These findings contrast with those of a large US community study, which found no differences in treatment-seeking behaviors among subjects with comorbid PTSD/AUD compared to those with a single diagnosis [4]. However, as mentioned in the Introduction section this finding might be due to the non-consideration of other important factors that empirically contribute to helpseeking behavior, which, however, were accounted for in the current study. The need for such a multi-factorial approach might be supported by the fact that even in our data a group effect only appeared after adjusting for other factors. Instead, Blanco et al. [4] suggested that a lower socio-economic status in those with PTSD/AUD might have limited the subjects' access to mental health services. This, 
however, was not the case in our sample as health care is accessible to the whole population of Switzerland irrespective of social class. An alternative explanation based on our own recent findings could be that PTSD avoidance type symptoms are the linking element for the cooccurrence of PTSD and AUD [12]. Thus, it is possible that a higher tendency to avoid trauma-related emotions and memories prevents one's efforts to seek help for these problems.

Although the literature suggests that comorbidity is generally associated with higher service utilization, especially due to higher rates of re-hospitalizations [34], the presence of comorbid AUD in particular was described to lower individual help-seeking efforts $[16,17]$. Since AUD as comorbid condition in those with PTSD is often understood as a consequence of a dysfunctional attempt to cope with the traumatic experience through an increased use of alcohol, it is possible that self-medication of PTSD symptoms decreases motivation to seek help [4].

Our findings provide some evidence for the self-medication hypothesis in comorbid PTSD/AUD [7, 9]. Whereas our data show that both groups with only one disorder were more likely to have ever used prescribed drugs for depression and/or anxiety disorders than individuals without any PTSD or AUD, this was not true for the comorbid group. Instead, subjects with both conditions were less likely to have ever used drugs for depression and anxiety disorders than those with PTSD alone. It seems likely that individuals with the comorbid condition, at least in some cases, use alcohol as an attempt to self-medicate their symptoms [35]. The current study suffers from several limitations that have to be acknowledged. First, the study was based on cross-sectional data with retrospectively reported help-seeking behaviors; and therefore causations cannot be proven. Similarly, the temporal sequence of PTSD and AUD in the comorbid group cannot be accurately accounted for with retrospectively assessed data. However, a comparison of recalled ages of onset within the comorbid group at least supported the assumption of PTSD onset before that of AUD in this 
special group. Furthermore, by using a lifetime definition of mental illness as well as of helpseeking we did not relate help-seeking behaviors to specific episodes of illness, and the information might be subject to recall bias. Another limitation is that we did not assess subjective psychological factors that may have affected helpseeking behaviors, such as perceived stigma, and other such barriers [36]. Previous research has shown that perceived clinical needs had more power than illness severity to predict whether individuals with mental disorders actually do seek help [37]. Furthermore, it would be interesting to understand how informal sources of help were utilized by our subjects and how this could have affected helpseeking behaviors geared towards professionals [38]. Finally, the rates of treatment seeking in our sample are much higher than those of other studies [4]. This is attributable to the fact that a large proportion of the study subjects reported having suffered from MDD over lifetime, from which almost $80 \%$ consulted a health care professional. The high prevalence of MDD in our study is most likely attributable to the very low threshold to enter the depression section in our DIGS version as well as the removal of the one-week duration specification in the screening questions for depression of the original DIGS in order assess subthreshold depressive syndromes. Accordingly, the large majority of the participants entered the depression section and more than half of them fullfilled criteria for a major depressive episode according to the DSM-IV. Then, the fact that we used a semi-structured interview, which was conducted by trained psychologists, unlike a structured interview, which is gathered by lay interviewers with no prior clinical knowledge, surely favored the recall of $\operatorname{MDD}[39,40]$. Despite the comparably high rate of MDD in the PTSD/AUD group in our study these subjects were still less likely to have benefitted from treatment or a drug prescription for depression or anxiety disorders than those PTSD alone.

\section{Conclusions}


Our findings show important differences between subjects with comorbid PTSD and AUD compared to those with either of these conditions. It shows a mismatch between a greater clinical need for treatment on the one hand and less frequent helpseeking behaviors on the other hand in this particular population. This unfavorable balance deserves special attention since it requires greater efforts to provide health care services for those individuals. Nevertheless, it also implies that clinicians should probe more deeply to investigate trauma and PTSD related symptoms in those with AUD. A direct referral to concurrent treatment of trauma/PTSD is recommended since integrated treatments were proven to be more successful for recovery, and AUD comorbid to PTSD requires different and more intensive counseling than for the AUD condition alone [41, 42]. If comorbid PTSD/AUD does indeed hamper helpseeking behavior, future epidemiological research should encourage efforts to investigate barriers to helpseeking and promoting illness insight in this particular population.

\section{Acknowledgements}

The PsyCoLaus study was and is supported by research grants from GlaxoSmithKline, the Faculty of Biology and Medicine of Lausanne, and the Swiss National Science Foundation (grants 3200B0-105993, 3200B0-118308, 33CSCO-122661, 33CS30-139468 and 33CS30148401). The funders had no role in the design of the study; the collection, management, analysis, and interpretation of the data; the preparation, review or approval of the manuscript; or the decision to submit the manuscript for publication. 


\section{References}

[1] Galatzer-Levy IR, Nickerson A, Litz BT, Marmar CR. Patterns of lifetime PTSD comorbidity: a latent class analysis. Depress Anxiety. 2013;30:489-96.

[2] Müller M, Vandeleur C, Rodgers S, Rossler W, Castelao E, Preisig M, et al. Factors associated with comorbidity patterns in full and partial PTSD: Findings from the PsyCoLaus study. Compr Psychiatry. 2014.

[3] Saladin ME, Brady KT, Dansky BS, Kilpatrick DG. Understanding comorbidity between PTSD and substance use disorders: two preliminary investigations. Addict Behav. 1995;20:643-55.

[4] Blanco C, Xu Y, Brady K, Perez-Fuentes G, Okuda M, Wang S. Comorbidity of posttraumatic stress disorder with alcohol dependence among US adults: results from National Epidemiological Survey on Alcohol and Related Conditions. Drug Alcohol Depend. 2013;132:630-8.

[5] Ouimette P, Moos RH, Finney JW. PTSD treatment and 5-year remission among patients with substance use and posttraumatic stress disorders. J Consult Clin Psychol. 2003;71:410-4.

[6] Stewart SH, Pihl RO, Conrod PJ, Dongier M. Functional associations among trauma, PTSD, and substance-related disorders. Addict Behav. 1998;23:797-812.

[7] Khantzian EJ. The self-medication hypothesis of substance use disorders: A reconsideration and recent applications. Harvard Review of Psychiatry. 1997;4:231-44.

[8] Khantzian EJ. Treating addiction as a human process. Northvale, NJ: Jason Aronson; 1999.

[9] Ouimette P, Read JP, Wade M, Tirone V. Modeling associations between posttraumatic stress symptoms and substance use. Addict Behav. 2010;35:64-7.

[10] Langeland W, Draijer N, van den Brink W. Psychiatric comorbidity in treatmentseeking alcoholics: the role of childhood trauma and perceived parental dysfunction. Alcohol Clin Exp Res. 2004;28:441-7.

[11] McLean CP, Su YJ, Foa EB. Posttraumatic stress disorder and alcohol dependence: does order of onset make a difference? J Anxiety Disord. 2014;28:894-901.

[12] Müller M, Vandeleur C, Rodgers S, Rossler W, Castelao E, Preisig M, et al. Posttraumatic stress avoidance symptoms as mediators in the development of alcohol use disorders after exposure to childhood sexual abuse in a Swiss community sample. Child abuse \& neglect. 2015.

[13] Beals J, Manson SM, Whitesell NR, Spicer P, Novins DK, Mitchell CM. Prevalence of DSM-IV disorders and attendant help-seeking in 2 American Indian reservation populations. Archives of general psychiatry. 2005;62:99-108.

[14] Skodol AE, Schwartz S, Dohrenwend BP, Levav I, Shrout PE, Reiff M. PTSD symptoms and comorbid mental disorders in Israeli war veterans. Br J Psychiatry. 1996;169:717-25.

[15] Maguen S, Cohen B, Cohen G, Madden E, Bertenthal D, Seal K. Gender differences in health service utilization among Iraq and Afghanistan veterans with posttraumatic stress disorder. J Womens Health (Larchmt). 2012;21:666-73.

[16] Bucholz KK, Dinwiddie SH. Influence of nondepressive psychiatric symptoms on whether patients tell a doctor about depression. Am J Psychiatry. 1989;146:640-4.

[17] Galbaud du Fort G, Newman SC, Boothroyd LJ, Bland RC. Treatment seeking for depression: role of depressive symptoms and comorbid psychiatric diagnoses. J Affect Disord. 1999;52:31-40.

[18] Andersen RM. Revisiting the behavioral model and access to medical care: does it matter? J Health Soc Behav. 1995;36:1-10. 
[19] Preisig M, Waeber G, Vollenweider P, Bovet P, Rothen S, Vandeleur C, et al. The PsyCoLaus study: methodology and characteristics of the sample of a population-based survey on psychiatric disorders and their association with genetic and cardiovascular risk factors. BMC psychiatry. 2009;9:9.

[20] Firmann M, Mayor V, Vidal PM, Bochud M, Pecoud A, Hayoz D, et al. The CoLaus study: a population-based study to investigate the epidemiology and genetic determinants of cardiovascular risk factors and metabolic syndrome. BMC Cardiovasc Disord. 2008;8:6.

[21] Goldberg DP. The detection of psychiatric illness by questionnaire. Oxford: Oxford University Press; 1972.

[22] Bettschard W, Bolognini M. Questionnaire de santé, GHQ-12. In: Guelfi JD, editor. L'évaluation clinique standardisée en psychiatrie. Tome I, Boulogne: Editions Médicales Pierre Fabre; 1996.

[23] Hollingshead AB. Four-factor Index of Social Status. Unpublished manuscript1975.

[24] Leboyer M, Barbe T, Gorwood P, Teherani M, Allilaire JF, Preisig M, et al. Interview diagnostique pour les études génétiques. Paris: Institut National de la Santé et de la Recherche Médicale; 1995.

[25] Nurnberger JI, Jr., Blehar MC, Kaufmann CA, York-Cooler C, Simpson SG, HarkavyFriedman J, et al. Diagnostic interview for genetic studies. Rationale, unique features, and training. NIMH Genetics Initiative. Arch Gen Psychiatry. 1994;51:849-59; discussion 63-4.

[26] Leboyer M, Maier W, Teherani M, Lichtermann D, D'Amato T, Franke P, et al. The reliability of the SADS-LA in a family study setting. Eur Arch Psychiatry Clin Neurosci. 1991;241:165-9.

[27] Endicott J, Spitzer RL. A diagnostic interview: the schedule for affective disorders and schizophrenia. Arch Gen Psychiatry. 1978;35:837-44.

[28] Preisig M, Fenton BT, Matthey ML, Berney A, Ferrero F. Diagnostic interview for genetic studies (DIGS): inter-rater and test-retest reliability of the French version. Eur Arch Psychiatry Clin Neurosci. 1999;249:174-9.

[29] Berney A, Preisig M, Matthey ML, Ferrero F, Fenton BT. Diagnostic interview for genetic studies (DIGS): inter-rater and test-retest reliability of alcohol and drug diagnoses. Drug Alcohol Depend. 2002;65:149-58.

[30] Perrin M, Vandeleur CL, Castelao E, Rothen S, Glaus J, Vollenweider P, et al. Determinants of the development of post-traumatic stress disorder, in the general population. Soc Psychiatry Psychiatr Epidemiol. 2014;49:447-57.

[31] StataCorp. Stata Statistical Software. Release 13 ed. College Station, TX: StataCorp LP; 2011.

[32] Müller M, Vandeleur C, Rodgers S, Rössler W, Castelao E, Preisig M, et al. Childhood adversities as specific contributors to the co-occurrence of posttraumatic stress and alcohol use disorders. Psychiatry Research. in press.

[33] Müller M, Vandeleur C, Rodgers S, Rössler W, Castelao E, Preisig M, et al. Childhood adversities as specific contributors to the co-occurrence of posttraumatic stress and alcohol use disorders. in revision.

[34] Lyons JS, McGovern MP. Use of mental health services by dually diagnosed patients. Hosp Community Psychiatry. 1989;40:1067-9.

[35] Leeies M, Pagura J, Sareen J, Bolton JM. The use of alcohol and drugs to selfmedicate symptoms of posttraumatic stress disorder. Depress Anxiety. 2010;27:731-6.

[36] Rusch N, Heekeren K, Theodoridou A, Dvorsky D, Muller M, Paust T, et al. Attitudes towards help-seeking and stigma among young people at risk for psychosis. Psychiatry Res. 2013;210:1313-5. 
[37] Mojtabai R, Olfson M, Mechanic D. Perceived need and help-seeking in adults with mood, anxiety, or substance use disorders. Archives of general psychiatry. 2002;59:7784.

[38] Rusch N, Muller M, Ajdacic-Gross V, Rodgers S, Corrigan PW, Rossler W. Shame, perceived knowledge and satisfaction associated with mental health as predictors of attitude patterns towards help-seeking. Epidemiol Psychiatr Sci. 2014;23:177-87.

[39] Eaton WW, Neufeld K, Chen LS, Cai G. A comparison of self-report and clinical diagnostic interviews for depression: diagnostic interview schedule and schedules for clinical assessment in neuropsychiatry in the Baltimore epidemiologic catchment area follow-up. Archives of general psychiatry. 2000;57:217-22.

[40] Brugha TS, Bebbington PE, Jenkins R. A difference that matters: comparisons of structured and semi-structured psychiatric diagnostic interviews in the general population. Psychological medicine. 1999;29:1013-20.

[41] Najavits LM, Gastfriend DR, Barber JP, Reif S, Muenz LR, Blaine J, et al. Cocaine dependence with and without PTSD among subjects in the National Institute on Drug Abuse Collaborative Cocaine Treatment Study. Am J Psychiatry. 1998;155:214-9.

[42] Ouimette PC, Moos RH, Finney JW. Two-year mental health service use and course of remission in patients with substance use and posttraumatic stress disorders. J Stud Alcohol. 2000;61:247-53. 
Need and helpseeking in comorbid PTSD and AUD

Table 1. Socio-economic sample characteristics and ages of PTSD or AUD onset for the total sample and the diagnostic subgroups

\begin{tabular}{|c|c|c|c|c|c|c|}
\hline & \multirow{2}{*}{$\begin{array}{l}\text { Total } \\
\mathrm{N}=3,694\end{array}$} & \multicolumn{5}{|c|}{ Diagnostic subgroups } \\
\hline & & $\begin{array}{l}\text { No } \\
\text { diagnosis } \\
(\mathrm{N}=3,144)\end{array}$ & $\begin{array}{l}\text { AUD alone } \\
(\mathrm{N}=403)\end{array}$ & $\begin{array}{l}\text { PTSD } \\
\text { alone } \\
(\mathrm{N}=116)\end{array}$ & $\begin{array}{l}\text { PTSD + } \\
\text { AUD } \\
(\mathrm{N}=31)\end{array}$ & p-value \\
\hline & $\begin{array}{l}\% \\
/ \text { mean } \pm S \\
\text { D }\end{array}$ & $\begin{array}{l}\% \\
/ \text { mean } \pm \text { SD }\end{array}$ & $\begin{array}{l}\% \\
/ \text { mean } \pm \text { SD }\end{array}$ & $\begin{array}{l}\% \\
/ \text { mean } \pm \text { SD }\end{array}$ & $\begin{array}{l}\% \\
/ \text { mean } \pm \text { SD }\end{array}$ & \\
\hline Sex female & 53.00 & 56.39 & 19.85 & 75.00 & 58.06 & $<.001$ \\
\hline Age & $\begin{array}{l}49.60 \pm 8 . \\
80\end{array}$ & $49.67 \pm 8.84$ & $49.23 \pm 8.56$ & $49.26 \pm 8.60$ & $49.18 \pm 9.15$ & .757 \\
\hline \multicolumn{7}{|l|}{ Education } \\
\hline $\begin{array}{r}\text { Not finished } \\
\text { compulsory school }\end{array}$ & 1.08 & 0.89 & 1.24 & 6.03 & 0.00 & $<.001$ \\
\hline Basic & 52.76 & 52.00 & 58.06 & 49.14 & 74.19 & \\
\hline Higher & 24.69 & 25.19 & 21.34 & 27.59 & 6.45 & \\
\hline University degree & 21.47 & 21.91 & 19.35 & 17.24 & 19.35 & \\
\hline SES & $\begin{array}{l}3.38 \pm 1.2 \\
7\end{array}$ & $3.40 \pm 1.27$ & $3.32 \pm 1.26$ & $3.01 \pm 1.34$ & $3.13 \pm 1.43$ & .005 \\
\hline
\end{tabular}


Need and helpseeking in comorbid PTSD and AUD

\begin{tabular}{|c|c|c|c|c|c|c|}
\hline Age of AUD onset & $\begin{array}{l}29.85 \pm 10 \\
.59\end{array}$ & - & $\begin{array}{l}29.90 \pm 10.4 \\
3\end{array}$ & - & $\begin{array}{l}29.30 \pm 12.7 \\
0^{\mathrm{a}}\end{array}$ & .765 \\
\hline Age of PTSD onset & $\begin{array}{l}23.41 \pm 14 \\
.17\end{array}$ & - & - & $\begin{array}{l}24.22 \pm 13.9 \\
5\end{array}$ & $\begin{array}{l}20.42 \pm 14.8 \\
1^{\mathrm{a}}\end{array}$ & .186 \\
\hline
\end{tabular}

Note: AUD = alcohol use disorders; PTSD = posttraumatic stress disorder; SES = socio-economic status; SD = standard deviation; ${ }^{a}$ mean difference between age of AUD onset and age of PTSD onset in the comorbid group $=-9.30(\mathrm{t}=-2.71 ; \mathrm{df}=2 ; \mathrm{p}=.011)$. 
Tab 2. Distribution of clinical characteristics for the total sample and by diagnostic group

\begin{tabular}{|c|c|c|c|c|c|c|c|c|}
\hline & & \multirow{2}{*}{$\begin{array}{l}\text { Total } \\
(\mathrm{N}=3,694)\end{array}$} & \multicolumn{6}{|c|}{ Diagnostic subgroups } \\
\hline & & & $\begin{array}{l}\text { No / other } \\
\text { diagnoses } \\
(\mathrm{N}=3,144 ; \\
85.11 \%)\end{array}$ & $\begin{array}{l}\text { AUD alone } \\
(\mathrm{N}=403 ; \\
10.91 \%)\end{array}$ & $\begin{array}{l}\text { PTSD alone } \\
(\mathrm{N}=116 ; \\
3.14 \%)\end{array}$ & $\begin{array}{l}\text { PTSD + AUD } \\
(\mathrm{N}=31 ; \\
0.84 \%)\end{array}$ & $\begin{array}{l}\text { p- } \\
\text { value }\end{array}$ & $\begin{array}{l}\text { Post-hoc } \\
\text { pairwise } \\
\text { comparisons }\end{array}$ \\
\hline & & $\begin{array}{l}\% \\
/ \text { mean } \pm \text { SD }\end{array}$ & $\% /$ mean \pm SD & $\% /$ mean \pm SD & $\begin{array}{l}\% \\
/ \text { mean } \pm \text { SD }\end{array}$ & $\% /$ mean \pm SD & & \\
\hline \multirow{5}{*}{$\begin{array}{l}\text { Type of lifetime } \\
\text { trauma - worst } \\
\text { event }\end{array}$} & Accident & 4.36 & 3.85 & 4.71 & 13.79 & 16.13 & $<.001$ & $\begin{array}{l}\text { PTSD,PTSD/AUD> } \\
\text { CON,AUD }\end{array}$ \\
\hline & Crime & 3.25 & 2.58 & 2.48 & 21.55 & 12.90 & $<.001$ & $\begin{array}{l}\text { PTSD,PTSD/AUD> } \\
\text { CON,AUD }\end{array}$ \\
\hline & War & 1.54 & 1.43 & 1.74 & 3.45 & 3.23 & .295 & \\
\hline & $\begin{array}{l}\text { Witnessing } \\
\text { Violence }\end{array}$ & 8.88 & 7.57 & 10.67 & 32.76 & 29.03 & $<.001$ & $\begin{array}{l}\text { PTSD,PTSD/AUD }> \\
\text { CON,AUD } \\
\text { AUD }>\text { CON }\end{array}$ \\
\hline & $\begin{array}{l}\text { Lifetime sexual } \\
\text { abuse }\end{array}$ & 3.11 & 1.91 & 2.48 & 28.45 & 38.71 & $<.001$ & $\begin{array}{l}\text { PTSD,PTSD/AUD> } \\
\text { CON,AUD }\end{array}$ \\
\hline Childhood & Any & 6.74 & 5.28 & 6.95 & 32.76 & 54.84 & $<.001$ & $\begin{array}{l}\text { PTSD,PTSD/AUD> } \\
\text { CON,AUD } \\
\text { PTSD/AUD>PTSD }\end{array}$ \\
\hline
\end{tabular}




\begin{tabular}{|c|c|c|c|c|c|c|c|c|}
\hline \multirow[t]{2}{*}{ trauma } & Sexual abuse & 2.22 & 1.30 & 2.23 & 18.10 & 35.48 & $<.001$ & $\begin{array}{l}\text { PTSD,PTSD/AUD> } \\
\text { CON,AUD } \\
\text { PTSD/AUD>PTSD }\end{array}$ \\
\hline & Other trauma & 4.52 & 3.98 & 4.71 & 14.66 & 19.35 & $<.001$ & $\begin{array}{l}\text { PTSD,PTSD/AUD> } \\
\text { CON,AUD }\end{array}$ \\
\hline \multirow{10}{*}{$\begin{array}{l}\text { Comorbid } \\
\text { conditions }\end{array}$} & MDD & 43.73 & 42.67 & 41.19 & 74.14 & 70.97 & $<.001$ & $\begin{array}{l}\text { PTSD,PTSD/AUD> } \\
\text { AUD,CON }\end{array}$ \\
\hline & GAD & 2.30 & 2.04 & 1.24 & 9.48 & 16.13 & $<.001$ & $\begin{array}{l}\text { PTSD,PTSD/AUD> } \\
\text { AUD,CON }\end{array}$ \\
\hline & Agoraphobia & 4.39 & 4.17 & 3.72 & 9.48 & 16.13 & $<.001$ & $\begin{array}{l}\text { PTSD,PTSD/AUD> } \\
\text { AUD,CON }\end{array}$ \\
\hline & Simple phobia & 15.90 & 15.72 & 14.89 & 22.41 & 22.58 & .165 & \\
\hline & Social phobia & 12.00 & 11.20 & 14.39 & 20.69 & 29.03 & $<.001$ & $\begin{array}{l}\text { PTSD,PTSD/AUD> } \\
\text { CON } \\
\text { PTSD/AUD>AUD }\end{array}$ \\
\hline & OCD & 1.27 & 1.21 & 0.50 & 3.45 & 9.68 & $<.001$ & $\begin{array}{l}\text { PTSD,PTSD/AUD> } \\
\text { AUD,CON }\end{array}$ \\
\hline & Panic disorder & 4.55 & 4.20 & 3.72 & 14.66 & 13.33 & $<.001$ & $\begin{array}{l}\text { PTSD,PTSD/AUD> } \\
\text { AUD,CON }\end{array}$ \\
\hline & Antisocial PD & 2.60 & 1.43 & 9.70 & 5.22 & 19.35 & $<.001$ & $\begin{array}{l}\text { AUD,PTSD,PTSD/ } \\
\text { AUD>CON } \\
\text { PTSD/AUD>PTSD }\end{array}$ \\
\hline & SUD & 6.17 & 4.10 & 20.84 & 5.17 & 29.03 & $<.001$ & $\begin{array}{l}\text { AUD,PTSD/AUD> } \\
\text { CON,PTSD }\end{array}$ \\
\hline & $\begin{array}{l}\text { Number of } \\
\text { comorbid } \\
\text { conditions }\end{array}$ & $.93 \pm 1.00$ & $.87 \pm .96$ & $1.10 \pm 1.06$ & $1.65 \pm 1.14$ & $2.26 \pm 1.48$ & $<.001$ & $\begin{array}{l}\text { AUD,PTSD,PTSD/ } \\
\text { AUD>CON } \\
\text { PTSD,PTSD/AUD> } \\
\text { AUD } \\
\text { PTSD/AUD>PTSD }\end{array}$ \\
\hline Suicidality & Suicide & 5.94 & 4.36 & 9.73 & 25.86 & 41.94 & $<.001$ & $\begin{array}{l}\text { AUD,PTSD,PTSD/ } \\
\text { AUD>CON }\end{array}$ \\
\hline
\end{tabular}




\begin{tabular}{|c|c|c|c|c|c|c|c|c|}
\hline & attempts & & & & & & & $\begin{array}{l}\text { PTSD,PTSD/AUD> } \\
\text { AUD }\end{array}$ \\
\hline & $\begin{array}{l}\text { Number of } \\
\text { lifetime suicide } \\
\text { attempts }\end{array}$ & $.09 \pm .55$ & $.06 \pm .41$ & $.17 \pm .95$ & $.51 \pm 1.18$ & $.65 \pm .91$ & $<.001$ & $\begin{array}{l}\text { AUD,PTSD,PTSD/ } \\
\text { AUD>CON } \\
\text { PTSD,PTSD/AUD> } \\
\text { AUD }\end{array}$ \\
\hline & $\begin{array}{l}\text { Age of first } \\
\text { suicide attempt }\end{array}$ & $\begin{array}{l}26.92 \pm 11.7 \\
9\end{array}$ & $27.11 \pm 11.15$ & $31.06 \pm 11.07$ & $26.88 \pm 14.70$ & $15.86 \pm 3.39$ & .041 & AUD $>$ PTSD/AUD \\
\hline \multirow[t]{2}{*}{ Functioning } & $\begin{array}{l}\text { Global } \\
\text { functioning at } \\
\text { worst time }\end{array}$ & $\begin{array}{l}54.65 \pm 19.3 \\
3\end{array}$ & $56.63 \pm 19.54$ & $45.39 \pm 13.32$ & $38.26 \pm 11.50$ & $35.32 \pm 11.25$ & $<.001$ & $\begin{array}{l}\text { CON>AUD,PTSD,P } \\
\text { TSD/AUD } \\
\text { AUD>PTSD,PTSD/ } \\
\text { AUD }\end{array}$ \\
\hline & $\begin{array}{l}\text { Functionally } \\
\text { impaired in } \\
\text { areas of work, } \\
\text { school / } \\
\text { apprenticeship }\end{array}$ & 19.38 & 17.34 & 26.43 & 40.52 & 54.84 & $<.001$ & $\begin{array}{l}\text { AUD,PTSD,PTSD/ } \\
\text { AUD>CON } \\
\text { PTSD,PTSD/AUD> } \\
\text { AUD }\end{array}$ \\
\hline
\end{tabular}

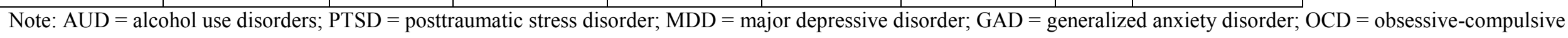
disorder; Antisocial PD = antisocial personality disorder; SUD = substance use disorders; CON = controls (no diagnosis of PTSD or AUD); SD = standard deviation. 
Tab 3. Distribution of helpseeking behaviors for the total sample and by diagnostic group

\begin{tabular}{|c|c|c|c|c|c|c|c|}
\hline & \multirow{2}{*}{$\begin{array}{l}\text { Total } \\
(\mathrm{N}=3,694)\end{array}$} & \multicolumn{6}{|c|}{ Diagnostic subgroups } \\
\hline & & $\begin{array}{l}\text { No diagnosis } \\
(\mathrm{N}=3,144)\end{array}$ & $\begin{array}{l}\text { AUD alone } \\
(\mathrm{N}=403)\end{array}$ & $\begin{array}{l}\text { PTSD alone } \\
(\mathrm{N}=116)\end{array}$ & $\begin{array}{l}\mathrm{PTSD}+\text { AUD } \\
(\mathrm{N}=31)\end{array}$ & p-value & $\begin{array}{l}\text { Post-hoc pairwise } \\
\text { comparisons }\end{array}$ \\
\hline & $\% /$ mean \pm SD & $\% /$ mean $\pm \mathrm{SD}$ & $\% /$ mean \pm SD & $\% /$ mean \pm SD & $\% /$ mean $\pm \mathrm{SD}$ & & \\
\hline $\begin{array}{l}\text { Seeking professional help for emotional } \\
\text { problems (lifetime) }\end{array}$ & 47.36 & 45.05 & 56.08 & 73.28 & 70.97 & $<.001$ & $\begin{array}{l}\text { AUD,PTSD,PTSD/AUD }>\text { CON } \\
\text { PTSD }>\text { AUD }\end{array}$ \\
\hline $\begin{array}{l}\text { Age of first professional help-seeking for } \\
\text { emotional problems }\end{array}$ & $34.82 \pm 12.00$ & $35.17 \pm 11.89$ & $34.22 \pm 12.57$ & $33.42 \pm 11.31$ & $23.73 \pm 10.13$ & $<.001$ & CON,AUD,PTSD $>$ PTSD/AUD \\
\hline Lifetime admission to psychiatric hospital & 6.15 & 4.64 & 13.93 & 15.65 & 22.58 & $<.001$ & AUD,PTSD,PTSD/AUD>CON \\
\hline Frequency of psychiatric hospital stays & $.14 \pm 1.19$ & $.10 \pm .91$ & $.30 \pm 1.02$ & $.40 \pm 1.87$ & $1.77 \pm 7.54$ & $<.001$ & $\begin{array}{l}\text { AUD,PTSD,PTSD/AUD>CON } \\
\text { PTSD/AUD>AUD,PTSD }\end{array}$ \\
\hline Age of first psychiatric hospitalization & $35.55 \pm 11.47$ & $34.61 \pm 10.97$ & $37.82 \pm 11.94$ & $35.68 \pm 13.86$ & $36.57 \pm 10.75$ & .368 & \\
\hline Lifetime treatment for depression & 8.88 & 8.30 & 11.41 & 14.66 & 12.90 & .019 & AUD,PTSD $>$ CON \\
\hline Lifetime treatment for anxiety disorders & 13.67 & 12.91 & 13.15 & 32.76 & 25.81 & $<.001$ & $\begin{array}{l}\text { PTSD,PTSD/AUD }>\text { CON } \\
\text { PTSD }>\text { AUD }\end{array}$ \\
\hline $\begin{array}{l}\text { Lifetime treatment for any depression or } \\
\text { anxiety disorders }\end{array}$ & 19.65 & 18.73 & 20.10 & 40.52 & 29.03 & $<.001$ & PTSD $>$ CON,AUD \\
\hline
\end{tabular}




\begin{tabular}{|c|c|c|c|c|c|c|c|}
\hline $\begin{array}{l}\text { Lifetime use of prescribed drugs for } \\
\text { depression }\end{array}$ & 22.12 & 20.83 & 25.06 & 43.97 & 32.26 & $<.001$ & PTSD $>$ CON,AUD \\
\hline $\begin{array}{l}\text { Lifetime use of prescribed drugs for anxiety } \\
\text { disorders }\end{array}$ & 29.59 & 27.86 & 33.75 & 56.03 & 51.61 & $<.001$ & $\begin{array}{l}\text { AUD,PTSD,PTSD/AUD>CON } \\
\text { PTSD,PTSD/AUD>AUD }\end{array}$ \\
\hline $\begin{array}{l}\text { Lifetime use of prescribed drugs for any } \\
\text { depression or anxiety disorders }\end{array}$ & 37.20 & 35.46 & 40.69 & 67.24 & 54.84 & $<.001$ & $\begin{array}{l}\text { AUD,PTSD,PTSD/AUD }>\text { CON } \\
\text { PTSD }>\text { AUD }\end{array}$ \\
\hline
\end{tabular}

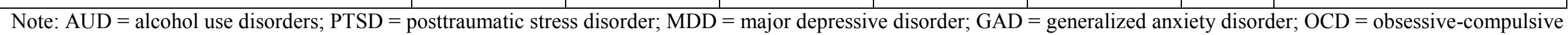

disorder; Antisocial PD = antisocial personality disorder; SUD = substance use disorders; CON = controls (no diagnosis of PTSD or AUD); SD = standard deviation. 
Need and helpseeking in comorbid PTSD and AUD

Tab 4. Multinomial logistic regression models: adjusted group comparisons for helpseeking behaviors

\begin{tabular}{|c|c|c|c|c|c|c|}
\hline & AUD alone & PTSD alone & PTSD + AUD & PTSD alone & PTSD + AUD & PTSD + AUD \\
\hline & \multicolumn{3}{|c|}{ Vs. no diagnosis } & \multicolumn{2}{|c|}{ Vs. AUD alone } & Vs. PTSD alone \\
\hline & OR $(95 \% \mathrm{CI})^{\mathrm{a}}$ & OR $(95 \% \mathrm{CI})^{\mathrm{a}}$ & OR $(95 \% \mathrm{CI})^{\mathrm{a}}$ & OR $(95 \% \mathrm{CI})^{\mathrm{a}}$ & OR $(95 \% \mathrm{CI})^{\mathrm{a}}$ & OR $(95 \% \mathrm{CI})^{\mathrm{a}}$ \\
\hline $\begin{array}{l}\text { Seeking help for } \\
\text { emotional problems } \\
\text { (lifetime) }\end{array}$ & $\begin{array}{l}1.77 * * *(1.39- \\
2.26)\end{array}$ & $1.76 *(1.10-2.80)$ & $.92(.37-2.30)$ & $.99(.59-1.66)$ & $.52(.20-1.33)$ & $.53(.19-1.45)$ \\
\hline $\begin{array}{l}\text { Age of first professional } \\
\text { help-seeking for } \\
\text { emotional problems (z- } \\
\text { scored) }\end{array}$ & $.92(.79-1.07)$ & $.96(.74-1.24)$ & $.42 * *(.26-.69)$ & $1.04(.78-1.39)$ & $.46 * *(.28-.76)$ & $.44 * *(.26-.75)$ \\
\hline $\begin{array}{l}\text { Admission to psychiatric } \\
\text { hospital }\end{array}$ & $\begin{array}{l}2.48 * * *(1.69- \\
3.65)\end{array}$ & $1.41(.77-2.59)$ & $1.35(.51-3.60)$ & $.57(.29-1.12)$ & $.54(.20-1.50)$ & $.96(.32-2.85)$ \\
\hline $\begin{array}{l}\text { Frequency of psychiatric } \\
\text { hospital stays (z-scored) }\end{array}$ & $1.07(.97-1.19)$ & $1.05(.92-1.19)$ & $1.11(.99-1.25)$ & $.97(.86-1.10)$ & $1.03(.93-1.15)$ & $1.06(.94-1.20)$ \\
\hline $\begin{array}{l}\text { Lifetime treatment for } \\
\text { depression }\end{array}$ & $\begin{array}{l}1.76 *(1.21- \\
2.55)\end{array}$ & $.90(.51-1.59)$ & $.66(.21-2.05)$ & $.51 *(.27-.98)$ & $.38(.12-1.21)$ & $.74(.22-2.51)$ \\
\hline
\end{tabular}




\begin{tabular}{|c|c|c|c|c|c|c|}
\hline $\begin{array}{l}\text { Lifetime treatment for } \\
\text { anxiety disorders }\end{array}$ & $.81(.60-1.17)$ & $1.46(.90-2.35)$ & $.50(.19-1.32)$ & $\begin{array}{l}1.79 *(1.01- \\
3.16)\end{array}$ & $.61(.22-1.68)$ & $.34 *(.12-.98)$ \\
\hline $\begin{array}{l}\text { Lifetime treatment for } \\
\text { any depression or } \\
\text { anxiety disorders }\end{array}$ & $1.04(.77-1.42)$ & $1.26(.80-1.99)$ & $.39 *(.15-.99)$ & $1.21(.71-2.05)$ & $.37 *(.14-.97)$ & $.31 *(.11-.85)$ \\
\hline $\begin{array}{l}\text { Lifetime use of } \\
\text { prescribed drugs for } \\
\text { depression }\end{array}$ & $1.36 *(1.02-1.80)$ & $1.48(.97-2.25)$ & $.57(.24-1.34)$ & $1.09(.67-1.78)$ & $.42(.17-1.02)$ & $.38 *(.15-.98)$ \\
\hline $\begin{array}{l}\text { Lifetime use of } \\
\text { prescribed drugs for } \\
\text { anxiety disorders }\end{array}$ & $1.30(1.00-1.70)$ & $1.61 *(1.04-2.49)$ & $.75(.32-1.76)$ & $1.24(.76-2.03)$ & $.58(.24-1.39)$ & $.47(.18-1.19)$ \\
\hline $\begin{array}{l}\text { Lifetime use of } \\
\text { prescribed drugs for any } \\
\text { depression or anxiety } \\
\text { disorders }\end{array}$ & $1.34 *(1.04-1.73)$ & $\begin{array}{l}1.89 * *(1.21- \\
2.97)\end{array}$ & $.59(.25-1.40)$ & $1.41(.85-2.33)$ & $.44(.18-1.07)$ & $.31 *(.12-.82)$ \\
\hline
\end{tabular}

Note : ${ }^{a}$ Adjusted for sex, age, education, socio-economic status, number of comorbid disorders, and suicidality; AUD = alcohol use disorders; PTSD = posttraumatic stress disorder; OR $(95 \% \mathrm{CI})=$ odds ratio $(95 \%$ confidence interval $)$; significant results are print in bold. 